\title{
GENERALIZED COMPOSITION OPERATORS FROM ZYGMUND TYPE SPACES TO $Q_{K}$ SPACES
}

\section{HAiYing Li, TiAnshui Ma And Zhitao GuO}

Abstract. Let $\varphi$ be an analytic self-map of $\mathbb{D}$ and $g \in H(\mathbb{D})$. The boundedness and compactness of generalized composition operators

$$
\left(C_{\varphi}^{g} f\right)(z)=\int_{0}^{z} f^{\prime}(\varphi(\xi)) g(\xi) d \xi, z \in \mathbb{D}, f \in H(\mathbb{D})
$$

from Zygmund type spaces to $Q_{K}$ spaces are investigated.

Mathematics subject classification (2010): 47B38. compact.

Keywords and phrases: Zygmund type space, $Q_{K}$ space, generalized composition operator, bounded,

\section{REFERENCES}

[1] C. C. Cowen AND B. D. MACCluer, Composition operators on spaces of analytic functions, CRC Press, Boca Roton, 1995.

[2] J. H. ShAPIRO, Composition Operators and Classical Function Theory, Universitext: Tracts in Mathematics. Springer-Verlag, New York, 1993.

[3] S. Li AND S. STEVIĆ, Generalized composition operators on Zygmund spaces and Bloch type spaces, J. Math. Anal. Appl. 338 (2008), 1282-1295.

[4] S. STEVIĆ, Generalized composition operators from logarithmic Bloch spaces to mixed-norm spaces, Util. Math. 77 (2008), 167-172.

[5] S. Stević And AJAY K. Sharma, Generalized composition operators on weighted Hardy spaces, Appl. Math. Comput. 218, 17 (2012), 8347-8352.

[6] F. ZHANG AND Y. LiU, Generalized composition operators from Bloch type spaces to $Q_{K}$ type spaces, J. Funct. Spaces Appl. 8, 1 (2010), 55-66.

[7] S. STEVIĆ, On an integral operator from Zygmund spaces to the Bloch-type space on the unit ball, Glasg. Math. J. 51 (2009), 275-287.

[8] S. STEVIĆ, Integral-type operators from a mixed norm space to a Bloch-type space on the unit ball, Siberian Math. J. 50, 6 (2009), 1098-1105.

[9] S. STEVIĆ, On an integral operator between Bloch-type spaces on the unit ball, Bull. Sci. Math. 134, 4 (2010), 329-339.

[10] S. Stević AND SEI-ICHIRo UeKI, On an integral-type operator between weighted-type spaces and Bloch-type spaces on the unit ball, Appl. Math. Comput. 217, 7 (2010), 3127-3136.

[11] S. STEVIĆ AND SEI-ICHIRO UEKI, Integral-type operators acting between weighted-type spaces on the unit ball, Appl. Math. Comput. 215, 7 (2009), 2464-2471.

[12] S. Li AND S. STEVIĆ, Volterra-type operators on Zygmund spaces, J. Inequal. Appl. 2007, Art. ID 32124, $10 \mathrm{pp}$.

[13] S. Li AND S. STEvić, Products of Volterra type operator and composition operator from $H^{\infty}$ and Bloch spaces to Zygmund spaces, J. Math. Anal. Appl. 345, 1 (2008), 40-52.

[14] S. Li AND S. STEVIĆ, Weighted composition operators from Zygmund spaces into Bloch spaces, Applied Mathematics and Computation 206, 2 (2008), 825-831.

[15] B. Choe, H. Koo And W. Smith, Composition operators on small spaces, Integr. Equ. Oper. Theory 56 (2006), 357-380. 
[16] K. ESMAEILI AND M. Lindström, Weighted composition operators between Zygmund type spaces and their essential norms, Integr. Equ. Oper. Theory 75 (2013), 473-490.

[17] S. YE AND Q. Hu, Weighted composition operators on the Zygmund space, Abstract and Applied Analysis 2012 (2012), Article ID 462482.

[18] P. L. Duren, Theory of $H^{p}$ Spaces, San Diego: Pure and Applied Mathematics 38, Academic Press, 1970.

[19] X. FU And S. LI, Composition operators from Zygmund spaces into $Q_{K}$ spaces, J. Inequal. Appl. 2013, 175 (2013).

[20] Y. REN, An integral-type operator from $Q_{K}(p, q)$ spaces to Zygmund-type spaces, Appl. Math. Comput. 236 (2014), 27-32.

[21] R. ZhaO, On a general family of function space, Ann. Acad. Sci. Fenn. Math. Diss., 1996.

[22] M. Essén, H. Wulan AND J. XiaO, Several function theoretic characterization of $Q_{K}$ spaces, J. Funct. Anal. 230 (2006), 78-115.

[23] H. Wulan, Compactness of the composition operators from the Bloch space to $Q_{K}$ spaces, Acta Math. Sin. 21 (2005), 1415-1424.

[24] S. LI, On an integral-type operator from the Bloch space into $Q_{K}(p, q)$ spaces, Filomat 26 (2012), $125-133$.

[25] S. STEVIĆ, On an integral operator on the unit ball in $\mathbb{C}^{n}$, J. Inequal. Appl. 1 (2005), 81-88.

[26] S. STEVIĆ, On an integral-type operator from Zygmund-type spaces to mixed-norm spaces on the unit ball, Abstr. Appl. Anal. 2010, Art. ID 198608, 7 pp.

[27] S. YAmashita, Gap series and $\alpha$-Bloch functions, Yokohama Math. J. 28 (1980), 31-36.

[28] A. Zygmund, Trigonometric series, Cambridge University Press, London, 1959. 